\title{
FORMULATION AND EVALUATION OF IN SITU GEL CONTAINING CIPROFLOXACIN HYDROCHLORIDE IN THE TREATMENT OF PERIODONTITIS
}

\author{
GORLE ASHISH*, YADAV RAHUL, RATHOD MUKESH, MALI PRAKASH
}

Department of Pharmaceutics, R C Patel Institute of Pharmaceutical Education and Research Shirpur, Dhule, Maharashtra 425405, India. Email: ashishgorle@rediffmail.com

Received: 06 February, 2017, Revised and Accepted: 11 March 2017

\section{ABSTRACT}

Objective: The present study describes the use of in situ gel in periodontal drug delivery systems which contain gellan gum (0.4-0.6\% w/v), pluronic F127 $(14,15$, and $16 \% \mathrm{w} / \mathrm{v})$, and drug ciprofloxacin $\mathrm{HCl}(0.1 \% \mathrm{w} / \mathrm{v})$. Number of peoples around the world suffered from dental problem and ultimate fear is tooth loss hence in situ gelling system was designed for the treatment of periodontal diseases. The therapeutic efficacy of drug can be greatly improved by prolonging its contact time.

Methods: Formulations were developed by simple solution method. Each formulation was characterized in terms of in gelling strength, viscosity, rheology, content uniformity, in vitro drug release, and syringeability.

Results: In vitro gelation time and the nature of the gel formed in simulated saliva for prepared formulations showed polymeric concentration dependency. Drug release data from all formulations were fitted to different kinetic models, and the Korsmeyer-Peppas model was the best fit model. Drug release was significantly decreased as the concentration of each polymer component was increased. Increasing the concentration of each polymeric component significantly increased viscosity, syringeability, and time for $50 \%, 70 \%$, and $90 \%$ drug release. In conclusion, the formulations described offer a wide range of physical and drug release characteristics. The formulation containing $0.6 \% \mathrm{w} / \mathrm{v}$ of gellan gum and $14 \% \mathrm{w} / \mathrm{v}$ of pluronic F127 exhibited superior physical characteristics. The formulation stored at $4^{\circ} \mathrm{C}$ before application, which is syringeable through 21 gauge needle.

Conclusion: This formulation was made to inject directly into periodontal pocket where it immediately converts into gel form at body temperature.

Keywords: Periodontitis, Poloxamer 407, Gelation temperature, Syringeability, Subgingival dental plaque.

(C) 2017 The Authors. Published by Innovare Academic Sciences Pvt Ltd. This is an open access article under the CC BY license (http://creativecommons. org/licenses/by/4. 0/) DOI: http://dx.doi.org/10.22159/ajpcr.2017.v10i6.17558

\section{INTRODUCTION}

Periodontal diseases are renowned as the main community problem worldwide. Dental diseases are surrounded by the most widespread chronic disorders affecting the human health. Periodontitis is an inflammation of the gingival and the deeper periodontal tissues. Periodontitis is pave the way and accompanied by gingivitis. However, gingivitis may persist without progressing to periodontitis foremost to the loss of supporting structure of teeth and the deeper tissues which affect the supportive structures of the teeth [1]. The periodontal pocket provides diverse surroundings for the immigration of gramnegative anaerobes such as Porphyromonas gingivalis, Bacteroides spp., Capnocytophaga spp., and Actinobacillus actionomycetemcomitns The bacteria build up in the periodontal pocket that widen between the roots of affected teeth and soft tissues [2]. If the disease is allowed to progress, increased tooth mobility and probably results in loss of tooth loss. As a result of pathologic changes, the gingival attachment to the tooth may become displaced, and a space forms between this detached gingiva and the tooth is called a pocket [3].

The ultimate result of progressive pocket formation leads to bone loss and tooth mobility. The systemic administration has been useful in treating periodontal pockets, but repetitive and extensive use of systemic drugs is burdened with potential danger including resistant strains and superimposed infections. To overcome the aforesaid drawbacks of conventional preparations, we tried to fabricate and to evaluate suitable drug delivery system with the aim of improving patient compliance, therapeutic efficacy, reduced dosing frequency and site specific drug action with adhesion and biodegradable polymeric systems. Local administration provides a useful answer to these problems. The antibacterial spectrum of Ciprofloxacin $\mathrm{HCl}$ includes bacteria such as the Peptostreptococcus species, Clostridium difficile, the Clostridium species, Bacteroids species, Bacteroids fragilis, Provotella species, Porphyromonas species, Fusobacterium species, Actinomycetes, Propionibacterium species, and the Eubacterium species. The drug is found to be most effectual against various Protozoa, namely, Trichomonas vaginalis, Entamoeba histolytica, and Giardiasis intestinalis. Bioadhesion may be defined as the condition in which two substances, at least one of them is from a biological source, are held together for extended periods of time by interfacial forces. For drug delivery purposes, the word bioadhesion involves the adhesion of a drug delivery system to a specific biological membrane. The biological surface can be epithelial tissue or the mucous coat on the surface of tissue. If hold attachment is to a mucous coat, the phenomenon is referred to as mucoadhesion [4].

In recent times, most of the scientists, students, researchers have paying attention on placing an API or API loaded formulations at a specific site in the body using bioadhesive water soluble polymers to control the delivery of biologically active agents systemically or locally [5] Biodegradable excipients have been used in drug delivery system. Because of their biodegradability, there is no any kind of requirement to take away the formulations exhausted with delivery devices. The exploitation of bioabsorbable delivery strategy represents a main step forward in the management of periodontal diseases. There remainder a call for in the art for the delivery device, which can be controlled more quickly and easily positioned in a periodontal pocket for the release of beneficial agent for a longer duration to treat the disease condition. The primary benefit of in situ gels is that they can be easily administer with precise \& reproducible dose compared with that of performed gels and have an advantage 
that they can be without difficulty instilled in liquid form, and are capable of make longer the residence time [6]

\section{MATERIALS AND METHODS}

\section{Materials}

Ciprofloxacin $\mathrm{HCl}$ was obtained as a gift sample from Alembic Pharmaceuticals Pvt. Ltd., Mumbai, India. Pluronic F-127 and Gellan gum (Kelcogel $囚$ ) was from Sigma-aldrich, Pvt. Ltd. (Germany), and purchased from Sudarshan Scientific Labortories, Nashik (MS) and Dialysis Membrane MWCO 12000 Da. Purchased from Hi Media (Mumbai, India) Deionised water was used as the aqueous component. Other all the chemicals used was of analytical grade.

\section{Microbiological material}

A bacterial and fungal strain was procured from microbial test culture collection (MTCC) Escherichia coli (MTCC 614), and Staphylococcus aureus (MTCC 1430). Nutrient agar and Potato dextrose agar was purchased from HiMedia Mumbai.

\section{Preformulation studies}

Tests were carried out on the sample of the drug to establish its identity and purity as per specification reported in Indian/British Pharmacopoeia. The parameters studied include appearance, solubility in different solvents, melting point, infrared spectra, determination of $\lambda_{\max }$ in phosphate buffer $\mathrm{pH} 7.4$ and distilled water [7].

Ultraviolet (UV) spectra were measured on (UV 1700, Shimadzu) double beam spectrophotometer to construct the standard curve for Ciprofloxacin $\mathrm{HCl}$ at $271 \mathrm{~nm}$. The melting point of Ciprofloxacin $\mathrm{HCl}$ was obtained by differential scanning calorimetry (DSC) study (Fig. 2). Infrared spectra of the physical mixture were analyzed by Fourier transform infrared (FTIR) (Shimadzu) (Fig. 1). DSC of pure drug and polymers were conducted using Differential Scanning Calorimetry (DSC $822 \mathrm{c}$, Mettler Toledo) at heating rate of $10^{\circ} \mathrm{C} /$ minutes over a temperature range of $35-300^{\circ} \mathrm{C}$ under an inert atmosphere flushed with nitrogen at a rate of $30 \mathrm{ml} /$ minutes. Drug-polymer interaction studies were performed by FTIR spectroscopy by KBr pellet method.

\section{Preparation of gel formulation}

Dry Gellan gum powder was dispersed in $90 \mathrm{ml}$ of distilled water maintained at $95^{\circ} \mathrm{C}$. The dispersion was stirred at $95^{\circ} \mathrm{C}$ for 20 minutes using a magnetic stirrer to facilitate hydration of gellan gum. The required amounts of preservatives (methylparaben and propylparaben) and disodium edetate were added to the gellan gum solution with continuous stirring at $95^{\circ} \mathrm{C}$. The solution was allowed to cool to room temperature. The required amount of Ciprofloxacin $\mathrm{HCl}$ was added to the gellan gum solution with continuous stirring until the entire

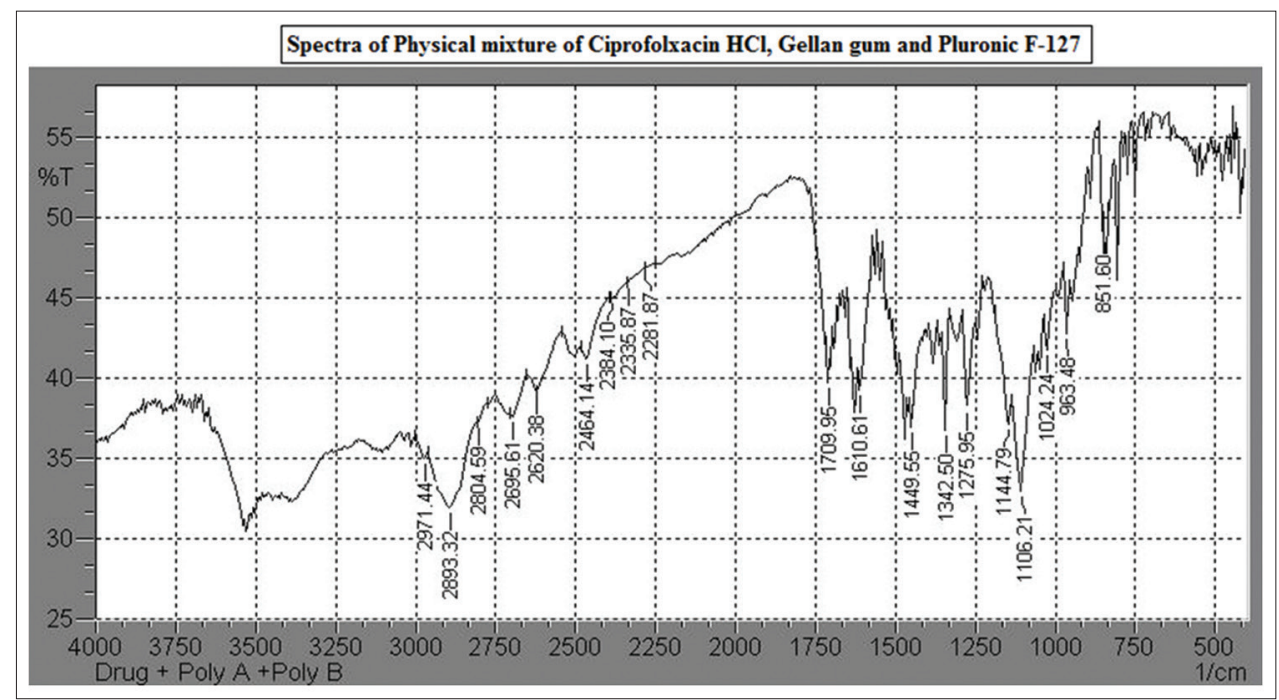

Fig. 1: Incompatibility study by Fourier transform infrared spectroscopy

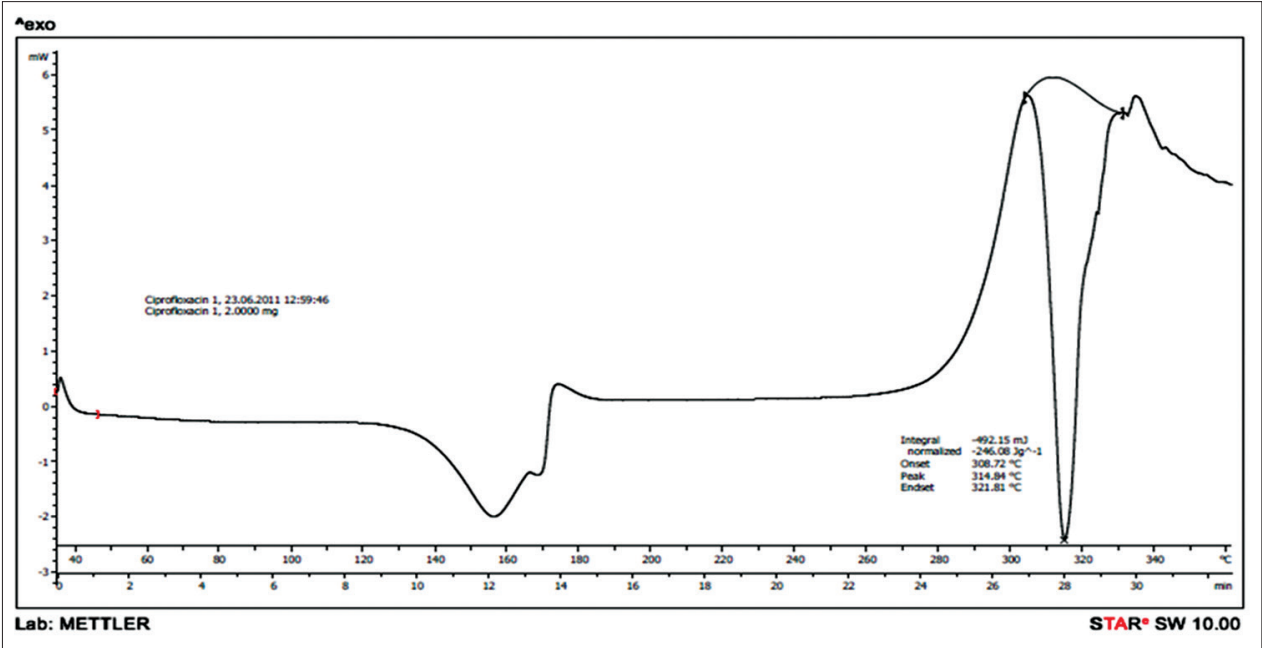

Fig. 2: Differential scanning calorimetry thermogram of pure drug 


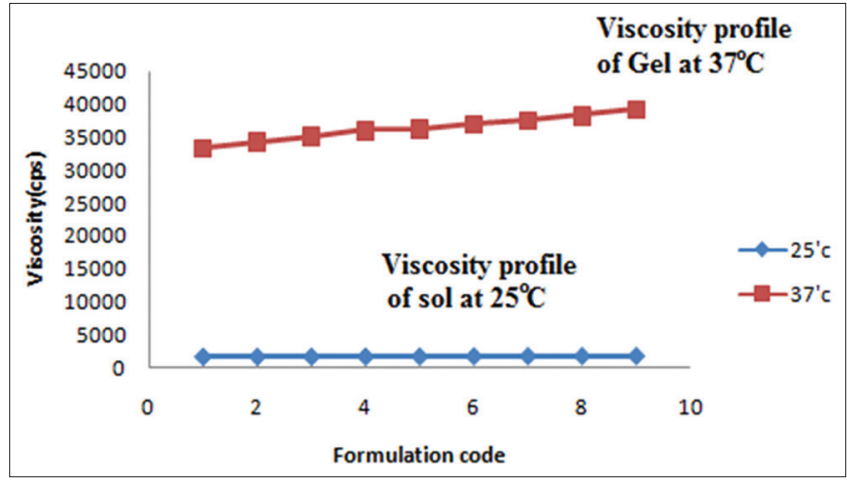

Fig. 3: Viscosity profile of sol at $25^{\prime} \mathrm{c}$ and gel $37^{\prime}$

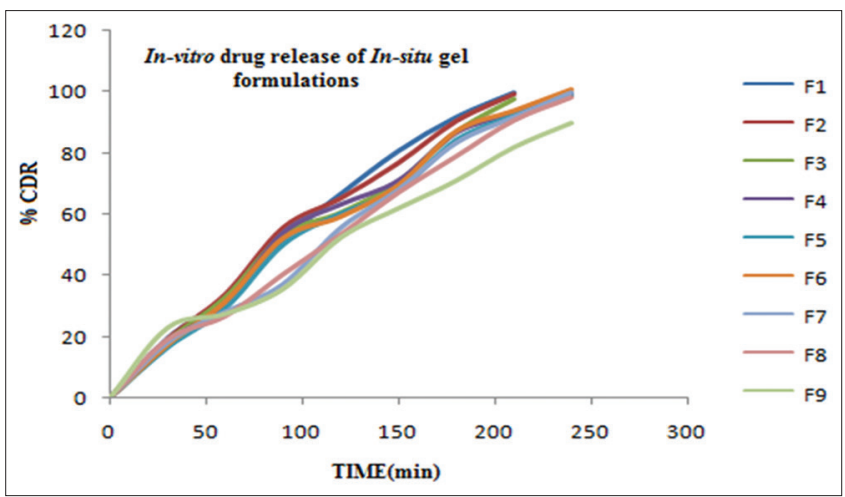

Fig. 4: In vitro drug release of in situ gel formulations

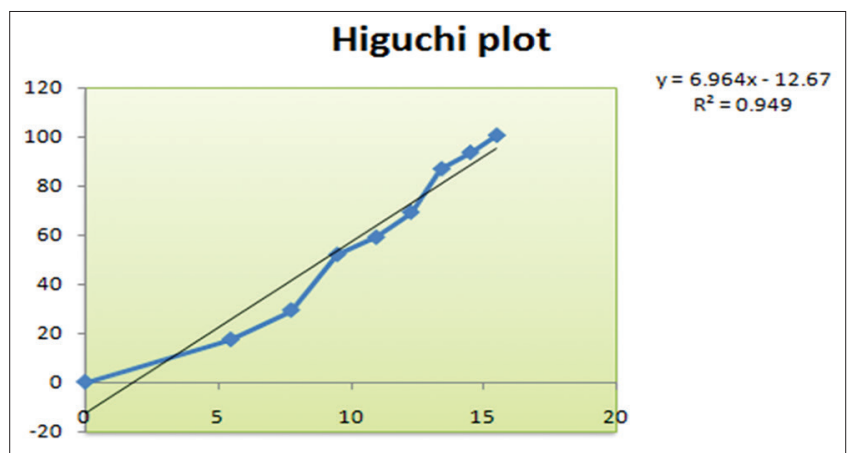

Fig. 5: Higuchi plot of formulation F7

drug was dissolved. The required amount of Pluronic F127 was added with continuous mild stirring for $5 \mathrm{~min}$. The formulations containing partially dissolved Pluronic F127 were stored in the refrigerator until the entire polymer was completely dissolved $(\sim 48 \mathrm{hrs})$. The formulations were prepared using different concentrations of gellan gum varying from $0.4 \%$ to $0.6 \% \mathrm{w} / \mathrm{v}$ and Pluronic F127 varying from $14 \%$ to $16 \% \mathrm{w} / \mathrm{v}$. The final volume was adjusted to $100 \mathrm{ml}$ with distilled, deionized water [8]. The composition of in situ gel is shown in Table 1.

\section{Evaluation parameter}

\section{Physical properties}

The appearances of formulations were observed by visual observation. The observed appearances of the prepared systems were tested on color, clarity.

\section{Drug content}

Formulations containing $1 \mathrm{mg}$ drug were taken in $10 \mathrm{ml}$ volumetric flask dissolve in distilled water then made up the volume to $10 \mathrm{ml}$ with distilled water then filtered. Absorbance values were measured with suitable dilutions of $2-14 \mu \mathrm{g} / \mathrm{ml}$ at $\lambda \max 271 \mathrm{~nm}$ by UV spectrophotometer. Concentrations of the drug were calculated from the standard calibration curve prepared in methanol as stated by to get the drug content [9].

\section{pH of formulation}

An acidic or alkaline formulation is bound to cause irritation on mucosal membrane, and hence this parameter assumes significance while developing a mucoadhesive formulation. $1 \mathrm{ml}$ of distilled water was added on to the formulation; $\mathrm{pH}$ was measured by allowing the electrode of a $\mathrm{pH}$ meter to come in contact with the formulation for 1 minute to equilibrate. A digital glass electrode $\mathrm{pH}$ meter was used for this purpose. $\mathrm{pH}$ was noted by bringing the electrode $\mathrm{pH}$ was noted by bringing the electrode near the formulations and allowing to equilibrate for 1 minute [8].

\section{Gelation study}

Gelation studies were carried out using temperature change and by the introduction of ions. In these studies the gelling capacity (speed and extent of gelation) for all formulations were determined. After easy instillation into periodontal pocket, the liquid polymeric solutions should undergo rapid sol to gel transition by means of thermosensitivity and ion-induced gelation. Thus, the in situ formed gel should preserve its integrity without dissolving or eroding so as to localize the drug at absorption site for the extended duration [10].

\section{In vitro gelling capacity}

The in vitro gelling capacity measurement of the formulations in the presence of cations (which are present in simulated saliva) was carried out by two methods.

\section{In vitro gelling capacity by visual method}

To evaluate the formulations for its in vitro gelling capacity by the visual method, colored solution of gel (batches F1-F9) were prepared. The in vitro gelling capacity of prepared formulations was measured by placing $2 \mathrm{ml}$ of simulated saliva in a $15 \mathrm{ml}$ borosilicate glass test tube and maintained at $37 \pm 1^{\circ} \mathrm{C}$ temperature. $1 \mathrm{ml}$ of colored formulation solution was added with the help of a $1 \mathrm{ml}$ pipette. The formulation was transferred in such a way that places the pipette at the surface of the fluid in the test tube and formulation was slowly released from the pipette. As the gel formulation comes into contact with simulated saliva, it was immediately converted into a stiff gel-like structure. The gelling capacity of gel was evaluated on the basis of stiffness and time period for which the formed gel remains as such. Color was added to give a visual appearance to the formed gel. The in vitro gelling capacity was graded in three categories on the basis of gelation time and time period for which the formed gel remains [11].

\section{In vitro gelling capacity by viscosity measurement}

Viscosities of formulations before and after gelation were measured using Brookfield DV-E viscometer using Spindle number-3 at $100 \mathrm{rpm}$ shear rate. In case of Pluronic F127 based systems, the viscosity was recorded at increasing temperature in the range of $20-30^{\circ} \mathrm{C}$ and graphs were plotted. From which an approximate gelation temperature was determined as indicated by sudden rise of viscosity [11];

- $\quad(+)$, gels after few minutes, dispersed rapidly;

- $(++)$, gelation immediate, remains for few hours;

- $(+++)$, gelation immediate, remains for an extended period.

Viscosity measurements viscosities of formulations before and after gelation were measured by using Brookfield DV-E viscometer using Spindle number 4 at $100 \mathrm{rpm}$ shear rate. In case of Pluronic F127 and gellan gum-based systems the viscosity was recorded at increasing temperature in the range of $20-30^{\circ} \mathrm{C}$, and the introduction of ions and graphs were plotted. From which an approximate gelation temperature was determined as indicated by the sudden rise of viscosity [12].

\section{Syringeability study}

All the developed formulations were tested syringeability through 21-gauge needle [13] 
Table 1: Composition of in situ gel

\begin{tabular}{|c|c|c|c|c|c|c|}
\hline \multirow[t]{2}{*}{ S. No. } & \multirow[t]{2}{*}{ Formulation code } & \multicolumn{5}{|c|}{ Formulation composition $(w / v) \%$} \\
\hline & & Ciprofloxacin $\mathrm{HCl}(\mathrm{w} / \mathrm{v}) \%$ & Gellan gum & Pluronic F-127 & Disodium edeatate & Distilled water (ml) \\
\hline 1 & $\mathrm{~F} 1$ & 0.1 & 0.4 & 14 & 0.1 & q.s. \\
\hline 3 & F3 & 0.1 & 0.4 & 16 & 0.1 & q.s. \\
\hline 4 & F4 & 0.1 & 0.5 & 14 & 0.1 & q.s. \\
\hline 5 & F5 & 0.1 & 0.5 & 15 & 0.1 & q.s. \\
\hline 6 & F6 & 0.1 & 0.5 & 16 & 0.1 & q.s. \\
\hline 7 & F7 & 0.1 & 0.6 & 14 & 0.1 & q.s. \\
\hline 8 & F8 & 0.1 & 0.6 & 15 & 0.1 & q.s. \\
\hline 9 & F9 & 0.1 & 0.6 & 16 & 0.1 & q.s. \\
\hline
\end{tabular}

All formulations were added with $0.18 \% \mathrm{w} / \mathrm{v}$ of methylparaben, $0.02 \% \mathrm{w} / \mathrm{v}$ of propylparaben

Table 2: Parameters for dependence of mechanism on $\mathbf{n}$ value

\begin{tabular}{ll}
\hline$>0.5$ & Quasi fickian \\
0.5 & Fickian diffusion \\
$0.5<\mathrm{n}<1.0$ & Anomalous (Non-fickian) transport \\
1.0 & Non fickian case II transport \\
$\mathrm{n}>1.0$ & Non fickian super case II \\
\hline
\end{tabular}

Table 3: Results of gelation study

\begin{tabular}{lll}
\hline S. No & Formulation code & Degree of gelation \\
\hline 1 & F1 & +++ \\
2 & F2 & +++ \\
3 & F3 & +++ \\
4 & F4 & ++++ \\
5 & F5 & ++++ \\
6 & F6 & ++++ \\
7 & F7 & ++++ \\
8 & F8 & ++++ \\
9 & F9 & ++++ \\
\hline
\end{tabular}

-: No gelation, +: Weak gelation, dissolves rapidly, ++: Immediate gelation remains for few hrs (less stiff gel), +++: Immediate gelation remains for extended period (Stiff gel), ++++: Very stiff gel

Table 4: Viscosity of sol at $25^{\circ} \mathrm{C}$ and gel at $37^{\circ} \mathrm{C}$

\begin{tabular}{|c|c|c|}
\hline \multirow[t]{2}{*}{ S. No } & \multicolumn{2}{|c|}{ Viscosity (cps) (mean \pm SD) } \\
\hline & $\begin{array}{l}\text { At room temp, i.e., } \\
25^{\circ} \mathrm{C} \pm 0.5 \text { in water }\end{array}$ & In simulated saliva at $37^{\circ} \mathrm{C} \pm 0.5$ \\
\hline 1 & $1674 \pm 3.6$ & $33317 \pm 2.5$ \\
\hline 2 & $1690 \pm 2.51$ & $34259 \pm 3.3$ \\
\hline 3 & $1684 \pm 3.6$ & $35128 \pm 2.6$ \\
\hline 4 & $1698 \pm 5.1$ & $35983 \pm 2.5$ \\
\hline 5 & $1732 \pm 5.5$ & $36231 \pm 2.4$ \\
\hline 6 & $1749 \pm 7.2$ & $36984 \pm 3.1$ \\
\hline 7 & $1784 \pm 5.5$ & $37431 \pm 1.9$ \\
\hline 8 & $1780 \pm 3.5$ & $38231 \pm 2.1$ \\
\hline 9 & $1797 \pm 2.6$ & $39189 \pm 3.8$ \\
\hline
\end{tabular}

Table 5: In vitro drug release study

\begin{tabular}{lll}
\hline S. No & $\begin{array}{l}\text { Formulation } \\
\text { code }\end{array}$ & Drug release (\%) at time $=\mathbf{2 4 0}$ minutes \\
\hline 1 & F1 & 99.78 \\
2 & F2 & 99.41 \\
3 & F3 & 97.58 \\
4 & F4 & 99.17 \\
5 & F5 & 98.53 \\
6 & F6 & 99.8 \\
7 & F7 & 100 \\
8 & F8 & 97.98 \\
9 & F9 & 89.76 \\
\hline
\end{tabular}

In vitro drug release kinetics

In vitro drug release study was performed using a Franz diffusion cell consisting of two glass compartments, a sampling port, a teflon coated magnetic stirrer bead, and a synthetic cellulose membrane $(0.45 \mu \mathrm{m})$. Simulated saliva having $\mathrm{pH} 7.4$ was used as a dissolution medium. The diffusion cell was water jacketed, and temperature was maintained at $37 \pm 1^{\circ} \mathrm{C}$ by continuous circulation of water, in a water bath with a minisubmersible pump. The Franz diffusion cell was placed on a magnetic stirrer, and the stirring rate was maintained at $\sim 250-300 \mathrm{rpm}$. After equilibration of the dissolution medium at $37 \pm 1^{\circ} \mathrm{C}, 1 \mathrm{ml}$ of sample was placed on synthetic cellulose membrane in the donor compartment of the cell with the help of a syringe. Before placing the formulation to the membrane $\sim 2 \mathrm{ml}$ of dissolution medium was placed on the membrane, and the whole assembly was allowed to equilibrate at $37 \pm 1^{\circ} \mathrm{C}$. At predetermined time intervals, $1 \mathrm{ml}$ samples of the receptor fluid were taken for 240 minutes. The medium was replaced after each sampling. Ciprofloxacin $\mathrm{HCl}$ concentration in each sample was determined by diluting $1 \mathrm{ml}$ of sample up to $100 \mathrm{ml}$ and analyzed spectrophotometrically at $271 \mathrm{~nm}$ using UV-visible spectrophotometer by Shimadzu, Japan [14].

The release data obtained was fitted into Korsmeyer-Peppas and Higuchi diffusion model to find the mechanism of release from the formulations [15].

The diffusion study reveals the pattern of drug release from the formulated gel. The in-vitro release data of formulation F7 was treated with Higuchi's diffusion equation.

$\left(\mathrm{Q}=\mathrm{kt}^{1 / 2}\right)$

The graph between percentage cumulative drug release and square root of time showed almost linear relationship after the initial period. The drug transport mechanism of the same formulations was determined using the Korsmeyer-Peppas exponential equation.

$\left[(\mathrm{Mt} / \mathrm{M})=k \mathrm{t}^{\mathrm{n}}\right]$

From the plot of $\log (\mathrm{Mt} / \mathrm{M})$; fraction of drug released at time " $\mathrm{t}$ " versus log of time. The kinetic parameters " $n$ " and " $k$ " were calculated from the equation. The calculated slop from the equation predicts the behavior of the drug release [16].

\section{Stability study}

Stability study was carried out on optimized formulation $\mathrm{F} 7$ at $30 \pm 2{ }^{\circ} \mathrm{C}$ temperature and $60 \pm 5 \%$ RH for 90 days. At a periodic interval, sample was withdrawn and was observed for clarity, $\mathrm{pH}$, viscosity, syringeability, and drug content at the interval of 30 days. All the measurements were performed after allowing the samples to equilibrate at $25^{\circ} \mathrm{C}$ [17].

\section{Anti-microbial activity}

The antimicrobial efficiency and prolonged effect of selected controlled release ciprofloxacin $\mathrm{HCl}$ in situ gel were determined on $S$. aureus and 
Table 6: Stability study data of F7 formulation

\begin{tabular}{|c|c|c|c|c|c|}
\hline \multirow[t]{2}{*}{ S. No } & \multirow[t]{2}{*}{ Parameters } & \multicolumn{4}{|c|}{ Storage period (days) at $30 \pm 2^{\circ} \mathrm{C}$ temperature and $60 \pm 5 \% \mathrm{RH}$} \\
\hline & & $\mathbf{0}$ & 30 & 60 & 90 \\
\hline 1 & Appearance & Clear white & Clear white & Clear white & Clear white \\
\hline 3 & Gelation study & +++ & +++ & ++ & ++ \\
\hline 4 & In vitro drug release $(\%)$ & 99.59 & 98.41 & 98.24 & 98.08 \\
\hline
\end{tabular}

E. coli strains as a function of time. The inhibitory effect of formulation on the studied microorganisms was evaluated using agar well diffusion test. Wells were punched into the nutrient agar previously seeded with test organisms and wells were filled with $100 \mu \mathrm{l}$ of the samples. After allowing diffusion of solution for two-hour the plates were incubated for $24 \mathrm{hrs}$ at $37^{\circ} \mathrm{C}$, and the diameters of inhibition zones were measured. The inhibitory effect of optimized gel formulation was compared with standard [18]

\section{RESULTS AND DISCUSSION}

IR spectra of drug and free polymers showed no matching peaks with the drug spectra. The characteristic peaks of the drug (1400-1000, $3400-3000,3050-3000,1718,1400-1200 \mathrm{~cm}^{-1}$ ) were also appeared in the spectra of all the drug- polymer combination which is evidence of no interaction between any of the polymer with drug or between both the polymers (Fg. 1).

Ciprofloxacin $\mathrm{HCl}$ was confirmed by DSC which exhibits a sharp melting endothermic peak at temperature of $314^{-} 318^{\circ} \mathrm{C}$ as shown in Fig. 2. Reported peak temperature was $312-314^{\circ} \mathrm{C}$. DSC thermogram showed that there was no any major difference in peak endothermic temperature when compared with pure drug's thermogram.

The prepared in situ gels containing ciprofloxacin $\mathrm{HCl}$ was found to be transparent, clear and the color of formulation was found to be yellowish.

The drug content of the formulations was found to be in the range of $98.2 \%$ and $99.54 \%$. Hence, on that basis, we can say that the drug was uniformly distributed throughout the formulation.

The $\mathrm{pH}$ of all the formulations prepared using a combination of gellan gum and lutrol F127, and a combination of both was observed in the range of 6.9-7.4. Therefore, there was no need for $\mathrm{pH}$ adjustment by any external alkalinizing agent.

All the formulations were tested as per that of the visual inspection and the time required to change the phase from sol-gel in physiological conditions (Table 3).

The viscosity of the selected formulations was measured at two different conditions.

\section{Formulations were prepared in distilled water}

Viscosity was measured at formulation $\mathrm{pH}$ and $25^{\circ} \mathrm{C}$ temperature.

\section{Formulations were prepared in simulated saliva}

Viscosity was measured at $\mathrm{pH} 7.4$ and $37^{\circ} \mathrm{C}$ temperature (physiological condition).

The apparent viscosity values were measured for liquid formulations and gel using Brookfield viscometer DV-E with spindle no. 3 at $100 \mathrm{rpm}$. The selected formulations were poured into the sample adaptor of the viscometer and viscosity was measured. The measurements were carried out using spindle no. 3 at the speed of 50-100 rpm in the sample and the viscosity was measured at $10 \mathrm{~min}$ after the rotation of the spindle. The viscosity measurements were made in triplicate using fresh samples each time (Table 4).
The marked increase in viscosity of the liquid (sol) formulations was increased from 1674.0 to $1797.0 \mathrm{cps}$ as the concentration of Pluronic F 127 increased from 14 to $16 \%$ and gellan gum was 0.4 to $0.6 \% \mathrm{w} / \mathrm{v}$. It was also seen that the viscosity of the gel formulation was increased from 33317 to $39189 \mathrm{cps}$ as the temperature and ions come in contact of the formulation (Fig. 3). Thus, increase in the concentration of the polymers leads to the increase in the viscosity of the formulation.

All the formulation was found to be easily injectable through 21 gauge needle at $25^{\circ} \mathrm{C}$ temperature. This facilitate to injection of sol directly into the periodontal pocket.

The in vitro drug release profiles of all the prepared formulations were executed using vertical Franz's diffusion cell (capacity: $14 \mathrm{ml}$ ) with synthetic dialysis membrane. Phosphate buffer $\mathrm{pH} 7.4$ was used as a diffusion media. Initially, an incomplete gel formation result in the quick release of drug, but the release rate was found to be significantly decreased with time due to complete gel formation. With increase in the concentration of pluronic F-127 and gellan gum the release rates were found to decrease gradually. The release profiles exhibited an inflection point, which indicated the gel formation in the donor compartment of the diffusion cell. During gel formation, a portion of drug might be loaded into the gel matrix, thus, the cross-linking of polymer reduces the drug release rate. The presence of aqueous phase exhibited the formation of porous prehydrated matrix. This results in the initial rapid release of drug from the prepared formulations. The results showed that the formed gels had the ability to extend the release of drug for the duration of about 240 minutes (Table 5)

In vitro release study indicated that the release of drug varied according to the type and concentration of polymers. The results further showed that the amount of the drug released in the first hour decreased with the increase in both the polymer concentration and this pattern continued till the entire duration of the study as shown in Figure 4.

To determine the release of a drug accurately from in situ gelling formulations, the cumulative percentage drug release data of formulation batch F7 was subjected to the Higuchi's diffusion equation $\left(\mathrm{Q}=\mathrm{kt}^{1 / 2}\right)$. Following the initial time period, the graph between percentage cumulative drug release and square root of time exhibited almost linear correlation. Owing to incomplete gel formation, it was not possible to correlate the drug release in the early phase of drug release study. As the gel is formed completely, the release profiles were found to be linear with the square root of time and followed the Higuchi's equation (Fig. 5). The slope of the plot of F7 formulations was observed to be 2.010, indicating the anomalous transport mechanism (Table 2). Based on the gelation properties, physicochemical characteristics and in vitro drug diffusion profiles, the formulation batch F7 was selected as an optimized in situ gelling formulation, and it was subjected for further studies.

The antibacterial study was carried out against the E. coli and S. aureus which is gram negative bacteria using test and standard formulation. The test sample and standard sample shows $52 \mathrm{~mm}$ and $45 \mathrm{~mm}$ for $E$. coli and $78 \mathrm{~mm}$ and $58 \mathrm{~mm}$ for $S$. aureus zone of inhibition, respectively. The inhibition rates to $E$. coli and $S$. aureus of the test and standard material after $24 \mathrm{hrs}$ is shown in Fig. $6 \mathrm{a}$ and b. These results can be attributed to the ability of ciprofloxacin hydrochloride in situ gel which inhibits the DNA gyrase of bacteria. This indicates 


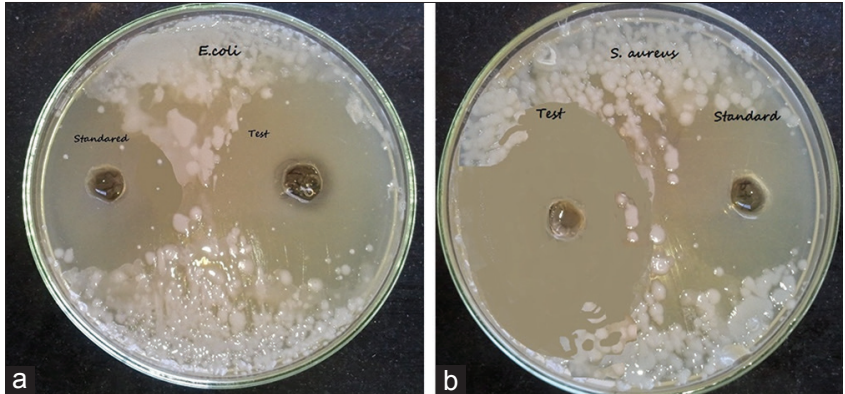

Fig. 6: Antibacterial activity (a) Escherichia coli (b) Staphylococcus aureus

that the test sample have better antibacterial activity as compared to a standard sample.

The stability study carried out on optimized formulation F7 at $30 \pm 2^{\circ} \mathrm{C}$ temperature and $60 \pm 5 \% \mathrm{RH}$ for 90 days. The formulation was showing good stability with no significant change in gelation and physicochemical properties and in vitro drug release profile as shown in Table 6. At a periodic interval sample were withdrawn and were observed for clarity, $\mathrm{pH}$, viscosity, syringeability, and drug content at the interval of 30 days. All the measurements were performed after allowing the samples to equilibrate at $25^{\circ} \mathrm{C}$.

\section{CONCLUSION}

In the present work formulations containing drug ciprofloxacin $\mathrm{HCl}$ by the use of gellan gum and Pluronic F-127, in situ gelling system was developed for the management of periodontal diseases. The developed formulation exhibited satisfactory findings from the aforesaid study. In vitro drug release studies showed a polymer concentrationdependent decrease in drug release. As the polymer concentration decreases the release rate profile increases. All the formulations developed by using different concentrations of gellan gum and Pluronic F-127 varying from 0.4 to $0.6 \%$ and $14-16 \%$ extend the release of drug up to a 3-4 hrs. The desired drug release and viscosity profile was executed by F7 containing $0.6 \% \mathrm{w} / \mathrm{v}$ gellan gum and $14 \% \mathrm{w} / \mathrm{v}$ pluronic F127 was considered as optimum formulation on the basis of optimum viscosity, in vitro drug release profile at initial period, and then its capacity to extend the release rate up to $4 \mathrm{hrs}$.

Thus, developed in situ gelling systems improves the patient's compliances, reduces the dose of the drug and related side effects, hence, the bioavailability of the drug increases. The formulated in situ gelling system shows a promising approach towards the treatment so in future such kind of drug delivery will be definitely helpful to periodontal patients.

\section{ACKNOWLEDGMENT}

We are thankful to the Principal, R. C. Patel Institute of Pharmaceutical Education and Research, Shirpur - 425405 (MS), India, for providing the laboratory facilities.

\section{REFERENCES}

1. Listgarten MA. Nature of periodontal diseases: Pathogenic mechanisms. J Periodontal Res 1987;22:172-8.

2. Slots J, Rams TE. Antibiotics in periodontal therapy: Advantages and disadvantages. J Clin Periodontol 1990;17:479-93.

3. Medlicott NJ, Rathbone MJ, Tukcer IG, Holborow DW. Delivery systems for the administration of drugs to the periodontal pocket. Adv Drug Deliv Rev 1994;13:181-203.

4. Duchene D, Touchord F, Pappas NA. Pharmaceutical and medical aspects of bioadhesive systems for drug administration. Drug Dev Ind Pharm 1988;14:283.

5. Chen WG, George CC. Adhesive and in vitro release characteristics of propranolol bioadhesive disc system. Int J Pharm 1992;82:61-6.

6. Anshul S, Renu S. A review on levofloxacin in situ-gel formulation. Asian J Pharm Clin Res 2015;8(1):37-41.

7. Prakasam K, Bukka R. Evaluation of cellulose polymers for Buccal film formulation of rasagiline. Asian J Pharm Clin Res. 2014;7(3):83-7.

8. Ariyana A, David S, Irma E, Dan HB. Formulation and in vitro evaluation of alginate based metronidazole periodontal gel. Asian J Pharm Clin Res 2014;7(1):223-7.

9. ShahS, Bhadra S. Mucoadhesive in-situ gel for transmucosal delivery of celecoxib. Int J Pharm Pharm Sci 2014;6(10):221-7.

10. Harish NM, Prabhu P, Charyulu RN, Gulzar MA, Subrahmanyam CV. Formulation and evaluation of in situ gels containing clotrimazole for oral candidiasis. Indian J Pharm Sci 2009;71(4):421-7.

11. Edsman K, Carlfore J, Petersson R. Rheological evaluation of poloxamer as an in situ gel for ophthalmic use. Eur J Pharm Sci 1998;6:105-12.

12. Joshi M, Bolmal U, Dandagi P. Formulation and evaluation of cefuroxime axetil sol gel for periodontits. Int J Pharm Pharm Sci 2014;6(7):498-503.

13. Patel KS, Vadalia KR, Patel JK. Development and evaluation of in situ gelling system for treatment of periodontitis. Int J Pharm Tech Res 2014;6(7):2102-12.

14. Sapra P, Dhaval D, Soniwala M, Chavda J. Development and optimization of in situ periodontal gel containing levofloxacin for the treatment of periodontal diseases. J Sci Innov Res 2013;2(3):607-26.

15. Bachhav HD, Savkare A, Karmarkar R, Derle D. Development of poloxamer based thermosensitive in situ ocular gel of betaxolol hydrochloride. Int J Pharm Pharm Sci 2015;7(6):287-91

16. Rawat S, Warade S, Lahoti S. In situ gel formulation of ornidazole for the treatment of periodontal disease. Curr Pharm Res 2010;1:61-9.

17. Gorle AP, Gattani SG. Design and evaluation of polymeric ocular drug delivery system. Chem Pharm Bull 2009:57(9):914-9.

18. Partha N, Snigdha P, Laxmidhar M. Formulation development and in vitro evaluation of dental gel containing ethanol extract of Tephrosia Purpurea Linn. Int J Pharm Pharm Sci 2016;8(80):132-41. 